\title{
AHP evaluation of different debris-removing methods Jingying $\mathrm{MiaO}^{1, \text { a }}$ \\ ${ }^{1}$ School of North China Electric Power University, Heibei 071000, China; \\ a1324934258@qq.com
}

Keywords: Orbit debris, AHP, pairwise comparison matrix, strategy

\begin{abstract}
To remove the orbit debris and find out an opportunity for private firms, four debris-removing methods are proposed for comparison to obtain a feasible and reasonable profit strategy. AHP is used to assess the weakness and strength of the four methods in three distinct periods. According to the data searched analysis, we divided the future 60 years into three periods. Considering multiple important influencing factors of the four debris-removing methods, the methods were evaluated by using AHP and three ranks are obtained with factor analysis in distinct periods. The optimal method in different periods is presented and some related advice is obtained according to the results in succession.
\end{abstract}

\section{Introduction}

Space debris is a production of human space activities, especially the objects without theirs original functions or any other functions, including the rocket bodies and satellites, which have finished their work, the rocket jets, the abandoned property in the process of mission operating, the debris produced in the collision in the space, and is the main pollution source of the space environment [1] [2].

After many collision accidents, people have find that the consequences will be disastrous once the debris cause a collision for their high moving speed. As a consequence, how to avoid and clear the orbit debris become a global problem and is desperately to be solved. According to the article wrote by Xiangwan Rui [3], the provided debris sweeping measures contains recovery, resistance attenuation, cube sail, laser and so on.

\section{Methods illustration of removing debris.}

- Space-based water jets: It will add small solid rocket motors with water jets to large pieces of space debris to stabilize the target, maneuver to lower orbits with lower risk of collision. Besides, these lower rails air resistance is larger so that the attenuation velocity of satellite orbits is faster than before [4].

- Laser: When a space debris is aimed, the laser is send out to radiate the space junk to gasification and borrow the reaction force to drive the space junk to be burned in the atmosphere [4].

- Cube Sail: Using sun sail with solar energy to mobile, the sail will be send to the low orbits with a small aircraft. The sail has two junk cleaning modes, for one thing, it will absorb the debris by spreading sail in the low orbits. For another, using the solar energy, it can dispose the debris of high orbits. When it accumulates enough debris, it will go off the satellite orbits by increasing resistance [4].

- Mechanical grapple: Using robot "grasping" technology, ejected by launch vehicle, the mechanical grapple can catch a big space junk and will bring the junk back to atmosphere to destroy with itself [4].

\section{The factors of distinct methods.}

There are many methods to sweep up the orbit debris, such as space-based water jets, laser, cube sail and the mechanical grapple. To find out how to assess the optimal method, we set four time-independent factors in allusion to four different methods to evaluate it, for example, cost, risks, 
benefits, as well as technology development.

Three periods.

With other researched data, after numerical analysis, according to numerical values law, we divided continuous time into three periods. Because the numerical values changes slightly for being limited in 0.1, we think this repartition is available.

The cost of these methods contains the productive cost and the repaired cost and is related to time. According to the average values we have find, the cost, probability, benefits, benefits recovery cycle, project cycle of space-based water jets, laser, cube sail and the mechanical grapple is as follows:

Table 1 The data in the first period

\begin{tabular}{|c|c|c|c|c|c|c|c|}
\hline \multirow{2}{*}{$\begin{array}{l}\text { Methods } \\
\text { Name }\end{array}$} & \multicolumn{2}{|c|}{ Cost/10000 dollars } & \multicolumn{2}{|c|}{ The risks probability } & \multirow{2}{*}{ Benefits } & \multirow{2}{*}{$\begin{array}{c}\text { Benefits } \\
\text { recovery cycle. }\end{array}$} & \multirow{2}{*}{$\begin{array}{l}\text { Project } \\
\text { cycle }\end{array}$} \\
\hline & $C_{p}$ & $C_{r}$ & $P_{\mathrm{w}}$ & $P_{r}$ & & & \\
\hline $\begin{array}{c}\text { space-b } \\
\text { ased } \\
\text { water } \\
\text { jets }\end{array}$ & 400 & 0 & 0.04 & 0 & 3500 & 1.5 & 2.5 \\
\hline laser & 700 & 100 & 0.02 & 0.2 & 5000 & 2.3 & 4 \\
\hline $\begin{array}{l}\text { cube } \\
\text { sail }\end{array}$ & 108 & 30 & 0.03 & 0.1 & 4000 & 5.0 & 10 \\
\hline $\begin{array}{l}\text { mechan } \\
\text { ical } \\
\text { grapple }\end{array}$ & 300 & $\mathbf{O}$ & 0.06 & 0 & 3000 & 1.3 & 2.5 \\
\hline \multicolumn{8}{|c|}{ Table 2 The data in the interim period } \\
\hline $\begin{array}{l}\text { Methods } \\
\text { Name }\end{array}$ & $\begin{array}{c}\mathrm{Cost} / 10 \\
C_{p}\end{array}$ & Cost/10000 dollars & \multicolumn{2}{|c|}{ The risks probability } & Benefits & $\begin{array}{c}\text { Benefits } \\
\text { recovery cycle. }\end{array}$ & $\begin{array}{c}\text { Project } \\
\text { cycle }\end{array}$ \\
\hline $\begin{array}{c}\text { space-b } \\
\text { ased } \\
\text { water } \\
\text { jets }\end{array}$ & 500 & $\mathbf{O}$ & 0.03 & $\mathbf{O}$ & 4000 & 1.2 & 2.3 \\
\hline laser & 850 & 90 & 0.03 & 0.2 & 5500 & 3.2 & 5.9 \\
\hline $\begin{array}{l}\text { cube } \\
\text { sail }\end{array}$ & 100 & 40 & 0.02 & 0.1 & 3900 & 2.9 & 5.7 \\
\hline $\begin{array}{l}\text { mechan } \\
\text { ical } \\
\text { grapple }\end{array}$ & 320 & $\mathbf{O}$ & 0.05 & $\mathbf{O}$ & 3200 & 1.1 & 2.4 \\
\hline \multicolumn{8}{|c|}{ Table 3 The data in the upper period } \\
\hline $\begin{array}{l}\text { Methods } \\
\text { Name }\end{array}$ & \multicolumn{2}{|c|}{ Cost/10000 dollars } & \multicolumn{2}{|c|}{ The risks probability } & Benefits & $\begin{array}{c}\text { Benefits } \\
\text { recovery cycle. }\end{array}$ & $\begin{array}{c}\text { Project } \\
\text { cycle }\end{array}$ \\
\hline $\begin{array}{c}\text { space-b } \\
\text { ased } \\
\text { water } \\
\text { jets }\end{array}$ & 550 & 0 & 0.02 & 0 & 4500 & 1.2 & 2.0 \\
\hline laser & 900 & 110 & 0.02 & 0.1 & 6000 & 2.3 & 4.3 \\
\hline $\begin{array}{c}\text { cube } \\
\text { sail }\end{array}$ & 90 & 20 & 0.01 & 0.1 & 4500 & 1.4 & 2.7 \\
\hline $\begin{array}{c}\text { mechan } \\
\text { ical } \\
\text { grapple }\end{array}$ & 290 & 0 & 0.04 & 0 & 3700 & 1.0 & 1.8 \\
\hline
\end{tabular}




\section{AHP evaluation.}

\section{- Evaluation process:}

The problem of finding out the optimal method is divided into three arrangements as the figure 1 showing. The first arrangement is the aim arrangement of choosing the optimal method. Four methods are proposed in the lowest level. The middle level is the criterion arrangement, which contains cost, risks, benefits, project cycle and benefits recovery cycle. The completive hierarchical structure of AHP evaluation is displayed below:

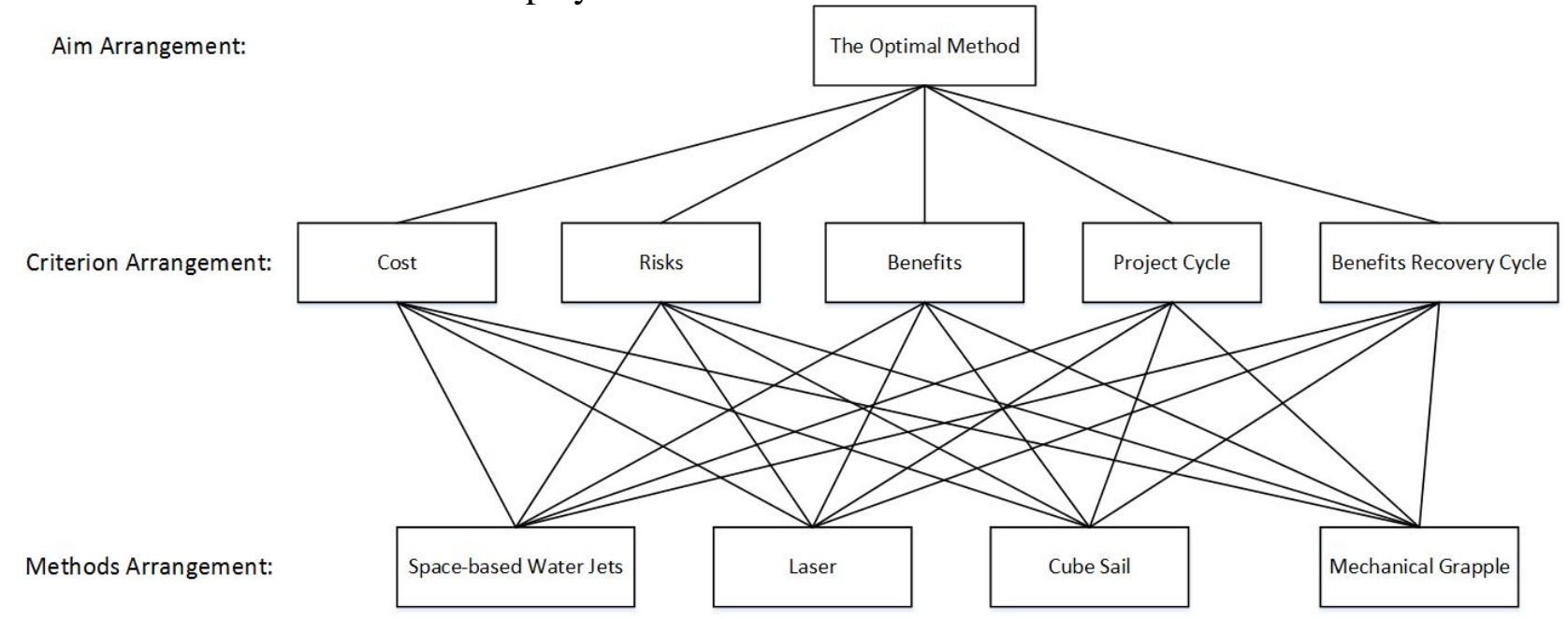

Fig 1: hierarchical structure of AHP evaluation

Using pairwise comparison matrix to show weight of each indicator, the optimal method evaluation factor judgment matrix $A$, cost, risks, benefits, project cycle, benefits recovery cycle judgment matrix $B_{1}, B_{2}, B_{3}, B_{4}, B_{5}$ were as follows. We take the first period as example there:

$$
\begin{aligned}
A & =\left[\begin{array}{lllll}
1 & 3 & 2 & 4 & 4 \\
\frac{1}{3} & 1 & \frac{1}{2} & 2 & 2 \\
\frac{1}{2} & 2 & 1 & 3 & 3 \\
\frac{1}{4} & \frac{1}{2} & \frac{1}{3} & 1 & 1 \\
\frac{1}{4} & \frac{1}{2} & \frac{1}{3} & 1 & 1
\end{array}\right] \\
B_{1} & =\left[\begin{array}{llll}
1 & 2 & \frac{1}{3} & \frac{1}{2} \\
\frac{1}{2} & 1 & \frac{1}{3} & \frac{1}{2} \\
3 & 3 & 1 & 2 \\
2 & 2 & \frac{1}{2} & 1
\end{array}\right] \\
B_{2} & =\left[\begin{array}{llll}
1 & \frac{1}{2} & 1 & 2 \\
2 & 1 & 1 & 3 \\
1 & 1 & 1 & 2 \\
\frac{1}{2} & \frac{1}{3} & \frac{1}{2} & 1
\end{array}\right]
\end{aligned}
$$


- Conclusion of AHP:

$$
\begin{aligned}
B_{3} & =\left[\begin{array}{llll}
1 & \frac{1}{3} & \frac{1}{2} & 2 \\
3 & 1 & 3 & 4 \\
2 & \frac{1}{3} & 1 & 3 \\
\frac{1}{2} & \frac{1}{4} & \frac{1}{3} & 1
\end{array}\right] \\
B_{4} & =\left[\begin{array}{llll}
1 & \frac{1}{2} & \frac{1}{3} & 1 \\
2 & 1 & \frac{1}{2} & 2 \\
3 & 2 & 1 & 3 \\
1 & \frac{1}{2} & \frac{1}{3} & 1
\end{array}\right] \\
B_{5} & =\left[\begin{array}{llll}
1 & \frac{1}{4} & \frac{1}{3} & \frac{1}{2} \\
4 & 1 & 2 & 3 \\
3 & \frac{1}{2} & 1 & 2 \\
2 & \frac{1}{3} & \frac{1}{2} & 1
\end{array}\right]
\end{aligned}
$$

Table 4 The results of AHP in the first period

\begin{tabular}{ccc}
\hline Methods name & Scores & Rank \\
\hline space-based water jets & 0.1842 & $(3)$ \\
laser & 0.3620 & $(1)$ \\
cube sail & 0.3118 & $(2)$ \\
mechanical grapple & 0.1420 & $(4)$ \\
\hline \multicolumn{2}{c}{ Table 5 The results of AHP in the interim period } & \\
\hline Methods name & Scores & Rank \\
\hline space-based water jets & 0.1942 & (3) \\
laser & 0.3300 & $(1)$ \\
cube sail & 0.3100 & $(2)$ \\
mechanical grapple & 0.1658 & ( \\
\hline Table 6 The results of AHP in the upper period & Rank \\
\hline Methods name & Scores & (3) \\
\hline space-based water jets & 0.1820 & (2) \\
laser & 0.3413 & (1) \\
cube sail & 0.3542 & (4)
\end{tabular}




\section{Summary}

In a conclusion, in the first period and the interim period, laser is the best investment project, the rest of the order is the cube sail, space-based water jets and the mechanical grapple. However, the cube sail become the best choice in the upper period, the rest is laser, space-based water jets and the mechanical grapple.

With analyzing about the data, we infer the reason why laser is the best programme is the working-time of laser is more than others and the reached mass of the debris is heavier than the rest. As for the cube sail, why it become the best project is that its cycle of working is shorter and the load capacity become bigger with the development of the technology. Meanwhile, according to our estimate data, the productive cost of cube sail is lower than before, but the productive cost of laser is higher than before. Furthermore, the wreck probability of cube sail is only 0.01, which is lower than the laser. For high input project like space industry, the risks probability have a far-reaching impact. According to assess of the judgment matrix before, the experts care risks more. Similarly, the low level of the space-based water jets and the mechanical grapple is their high risks. As a consequence, if the governments want to have more firms to invest these low level projects, the governments need to invest more to the technology development to decrease the risks.

\section{References}

[1]http://baike.baidu.com/link?url=Y_tOvmpbu9RzySxfHjewIXcco1imWNVN0h4dwEj-TragN-pb 6MenJ7vbcksW1gWJK04tjUCTc6K9H5OB6aak_

[2] 7B3TORxa4PU58lkSSc1WNeYhY3MpVBSL3r11apmSFxo

[3] Rui Xiang Wan, Zhang Taiwan. Current situation of space debris environment, the future and the protection of the [J]. Spacecraft engineering, 1994 (3): 42-60.

[4] http://m.sohu.com/n/402680856/?qq-pf-to=pcqq.c2c 